\title{
Whole-Body Vibration Training During a Low Frequency Outpatient Exercise Training Program in Chronic Obstructive Pulmonary Disease Patients: A Randomized, Controlled Trial
}

\author{
Marc Spielmanns ${ }^{\mathrm{a}, \mathrm{b}, \mathrm{h}, \mathrm{i}}$, Rainer Gloeckl c, d, h, Jana Marie Gropp ${ }^{\mathrm{a}}$, Christoph Nelle, \\ Andreas Rembert Koczulla ${ }^{\mathrm{e}}$, Tobias Boeselt ${ }^{\mathrm{e}}$, Jan Hendrik Storref, g, \\ Wolfram Windisch ${ }^{b, f}$
}

\begin{abstract}
Background: The aim of the study was to investigate whether wholebody vibration training (WBVT) can be applied beneficially within an outpatient low frequency exercise program.

Methods: In a prospective, controlled, randomized study, WBVT effectiveness and safety were investigated in COPD stage II-IV patients undergoing a 3-month training program. Participants took part in a 90-min circuit training once a week. On top patients were randomized to either perform squats with WBVT, or without (conventional training group (CTG)). Before and after the intervention, a sit-to-stand test (STST), a 6-min walk test (6-MWT), the COPD assessment test (CAT), and the chronic respiratory disease questionnaire (CRQ) were evaluated.
\end{abstract}

Results: Twenty-eight out of 55 patients completed the study $(\mathrm{n}=12$ WBTV, $\mathrm{n}=16 \mathrm{CTG})$. The STST time remained nearly constant for the CTG $(\Delta-0.8 \pm 3.1 \mathrm{~s})$ and the WBVT $(\Delta 1.4 \pm 3.2 \mathrm{~s} ; \mathrm{P}=0.227)$, respectively. Similarly, for both WBVT and CTG, the 6-min walk distance remained unchanged $(\Delta 7 \pm 55 \mathrm{~m}$ vs. $9 \pm 45 \mathrm{~m}, \mathrm{P}=0.961)$. In three out of four categories, the CRQ scores showed a significant improvement within WBVT, and in one category when comparing across groups. The CAT score dropped by $-0.8 \pm 2.9$ points within CTG and by $2.4 \pm 2.7$ points within WBVT $(\mathrm{P}=0.105)$. There were

Manuscript accepted for publication September 27, 2016

${ }^{a}$ Medical Clinic and Pulmonary Rehabilitation in Leverkusen (April), Remigius Hospital, Leverkusen, Opladen, Germany

${ }^{b}$ Faculty of Health, Department of Pneumology, University of Witten/Herdecke, Germany

'Department of Respiratory Medicine \& Pulmonary Rehabilitation, Schoen Klinik Berchtesgadener Land, Schoenau am, Koenigssee, Germany

${ }^{\mathrm{d}}$ Department of Prevention, Rehabilitation and Sports Medicine, Klinikum Rechts der Isar, Technische Universitat Munchen (TUM), Munic, Germany

ePulmonary Rehabilitation, Phillips University Marburg, Germany

fDepartment of Pneumology, Cologne Merheim Hospital, Kliniken der Stadt Koeln GmbH, Germany

gDepartment of Pneumology, University Hospital, Freiburg, Germany

${ }^{\text {h}}$ These authors contributed equally to this study.

${ }^{\mathrm{i} C}$ Corresponding Author: Marc Spielmanns, Medical Clinic and Pulmonary Rehabilitation in Leverkusen (April), St. Remigius Krankenhaus, An St. Remigius 26 ; 51379 Leverkusen, Germany. Email: spielmanns@k-plus.de

doi: https://doi.org/10.14740/jocmr2763w no adverse events related to WBVT.

Conclusion: The implementation of WBVT in the context of an outpatient low frequency exercise program did not significantly improve the patients' exercise capacity. An improvement in CAT and partially in CRQ was shown within WBVT. However, regarding the high dropout rate $(49 \%)$, these results must be interpreted with caution.

Keywords: Whole-body vibration training; Pulmonary rehabilitation; COPD; Sit-to-stand test; 6-min walk test; Exercise training

\section{Introduction}

The clinical relevant benefits of pulmonary rehabilitation in patients with chronic obstructive pulmonary disease (COPD) are proven on a high level of evidence [1]. Furthermore, pulmonary rehabilitation following an exacerbation of COPD leads to a reduction of re-hospitalization [2] and mortality [3] and can positively influence the progression of COPD [4].

Physical training represents a major component of pulmonary rehabilitation programs $[5,6]$. While the Anglo-American hemisphere emphasizes exercise training only [7], a multidisciplinary approach of pulmonary rehabilitation is preferred in Germany [8]. Since benefits of rehabilitation usually diminish about 1 year after such programs, the question of sustainability is discussed on national and international levels. In Germany, outpatient post-rehabilitation programs are established amongst others, and its policies as well as content are regulated for this purpose [9]. The content of these follow-up programs (usually low frequency and low intensity) is well documented and thoroughly described elsewhere $[10,11]$.

The advantage of using whole-body vibration training (WBVT) in different rehabilitation programs like patients with osteoporosis or neurological illness has been investigated extensively $[12,13]$. The method has been also evaluated in a recent study during an inpatient rehabilitation program of patients with severe to very severe COPD. The study by Gloeckl et al showed a significantly larger increase in exercise capacity when patients trained with WBVT in addition to conventional endurance and strength training [14]. As a training device for WBVT, a side alternating vibration platform $\left(\right.$ Galileo $\left.^{\circledR}\right)$ was used. The concept 


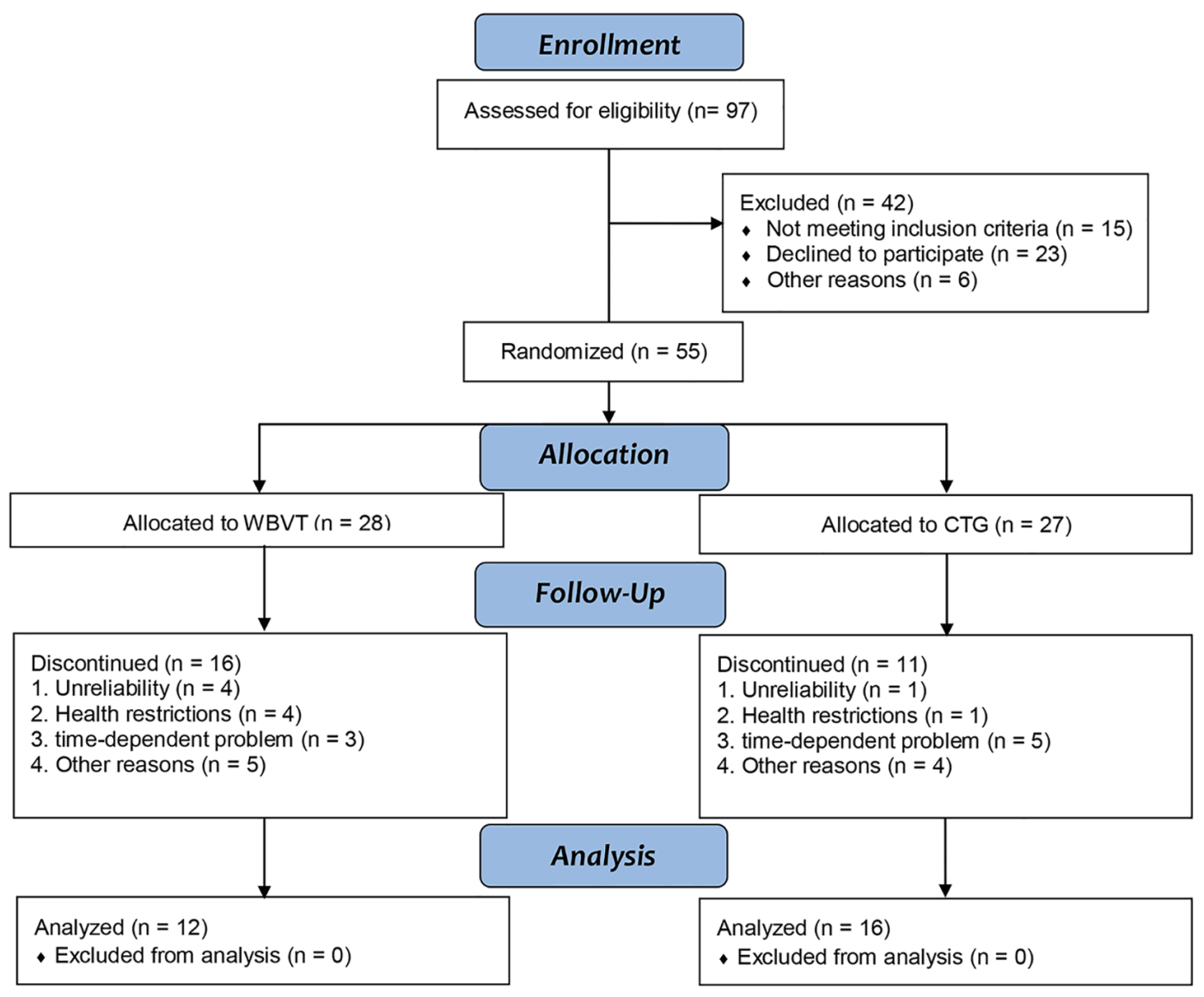

Figure 1. Study flow chart. WBVT: intervention group with whole-body vibration training; CTG: conventional training group.

of WBVT is based on imitating a human's natural walking motion sequence. The fast side alternating movement simulates the walking motion sequence with adjustable amplitude and frequency. As a natural mechanism to this kind of vibration, the body reacts by contracting muscles alternatively in the lower left and right extremities. Beyond a frequency threshold of $10-12$ $\mathrm{Hz}$, these muscle contractions are not voluntary anymore, but are induced by muscle stretch reflexes [15]. WBVT activates muscles from the legs up to the torso, increases the perfusion especially in the legs, and stimulates the overall blood circulation.

We hypothesized that a complementary WBVT could also be used as an effective training supplement in a low frequency and low intensity outpatient exercise program in COPD patients. The primary aim of this study was to investigate whether WBVT would lead to a significant increase in the five-repetition sit-to-stand test (STST) in comparison to a non-WBVT training group.

\section{Methods}

\section{Setting and study design}

The study represents a prospective, randomized and con- trolled interventional study at the St. Remigius Hospital in Leverkusen, Germany. Patients participated in an outpatient exercise training program once a week. In total, 94 patients with COPD were screened for eligibility from November 2013 through September 2015. Following the examination of inclusion and exclusion criteria, a detailed explanation was given and patients signed informed consent. Randomization was performed according to a computer-generated randomization list provided by the study statistician using a 1:1 randomization without block randomization. The group allocation was performed by a third party not being involved in patient recruitment. Group allocation was done after patients have signed informed consent. The study flow chart is presented in Figure 1. The ethics commission of the University of WittenHerdecke has verified the study (No. 124/2013). Then, the study was registered in the German Clinical Trials Register (DRKS No. 00006070).

\section{Inclusion criteria}

Patients with COPD at stages II-IV according to GOLD guideline were included [1]. Patients had to be willing to complete the training entirely. Furthermore, they had to participate in pre- and post-assessments at the outpatient center. The partici- 
pants had to give a written consent to the data acquisition and study participation.

\section{Exclusion criteria}

Exclusion criteria were acute COPD exacerbation within the last 28 days prior to study inclusion and presence of any contraindication for WBVT (e.g. artificial joint replacement, recent or planned surgery, a history of deep vein thrombosis or known aortic aneurysm).

\section{Measurements}

Initially, the inclusion and exclusion criteria were reviewed. In the beginning and the end of the training intervention, patients performed the following assessments: 6-min walk test (6-MWT), five-repetition STST, the 1-min STST, body plethysmography, COPD assessment test (CAT) and chronic respiratory disease questionnaire (CRQ).

\section{Pulmonary function testing}

Spirometry and body plethysmography (PowerCube, Fa.Ganshorn $^{\mathrm{TM}}$, Germany) were conducted in the beginning and the end of the study, while respecting the guidelines of the American Thoracic Society [16, 17], and utilizing reference values of the European Respiratory Society (ERS) [18].

\section{STST}

STSTs were carried out with a chair of standard height $(46 \mathrm{~cm})$. To avoid support with the arms, patients were asked to cross them in front of the chest. Initially, the test was demonstrated by an experienced colleague and then performed by the participant. Two STST versions were used. Firstly, the participants were asked to conduct the motion in their own pace as often as possible within $1 \mathrm{~min}$ (1-min STST). Attention was given towards a full extension of lower extremities. The amount of fully completed repetitions was recorded as outcome parameter. Patients were allowed to use rest periods to complete the 1-min test, if necessary [19].

Following, after a 15-min break, the second STST version was performed. Here, the time the patient needed to complete five repetitions of getting up and sitting down as quick as possible, was measured (five-repetition STST).

\section{6-MWT}

Participants were asked to walk as far as possible on a $30-\mathrm{m}$ track back and forth in their own pace (without running), adhering to the guidelines for the 6-MWT of the American Thoracic Society [20].

\section{Health-related quality of life}

$C R Q$

The health-related quality of life was assessed using the German version of the CRQ. The CRQ consists of four domains namely dyspnea, fatigue, emotional function and mastery. Evaluation of the individual domains reaches from 1 (major impairment) to 7 (without impairment) [21].

\section{$C A T$}

The questionnaire, filled in by the patients themselves, evaluates the global impact of the COPD (e.g. cough, expectoration, dyspnea, and stenocardia) on the health status. Each of the eight questions is rated between 0 and 5 points resulting in a maximum score of 40 points. A score of 0 is the best possible result. Higher values indicate a serious negative impact of COPD on the participant's quality of life [22].

\section{Intervention}

Within the outpatient pulmonary rehabilitation groups, participants were randomly assigned to a CTG or a WBVT group. In each training session, the WBVT group performed squat exercises on the side-alternating Galileo vibration platform (Novotec Medical, Pforzheim, Germany). Patients performed three sets of up to 20 squat repetitions with a frequency of $24-26 \mathrm{~Hz}$ and an amplitude of $3 \mathrm{~mm}$. Training was conducted shoeless and in following sequence: slightly bended knees $\left(10-20^{\circ}\right)$, standing and bending of $30-40^{\circ}$ without holding on with arms. The CTG conducted the same amount of squat exercises but without WBVT. The remaining content of the training stayed the same and had a duration of 90 min per unit. It included exercises with dumbbells and Thera-band ${ }^{\mathbb{R}}$, different modalities of walking, ergometer training, stair climbing, dance, and more. It furthermore consisted of endurance training and rolling walker training orientating at activities of daily living. The full training content is described extensively elsewhere [11]. Over the course of 3 months, the described training was continued once a week. All adverse events occurring during or after the training, e.g. cardiac incidents or injuries, as were noted.

\section{Trial objectives}

The primary objective was the change in measured time of the five-repetition STST in group comparison, while the secondary objectives were changes in 6-min walk distance (6MWD), 1-min STST, CAT, CRQ and adverse events recorded by the participants or the staff.

\section{Statistical analysis}

A significance value of $5 \%$, power of $80 \%$ in combination with 
Table 1. Anthropometric Data, Baseline Characteristics

\begin{tabular}{llll}
\hline & $\begin{array}{l}\text { WBVT } \\
(\mathbf{n = 1 2})\end{array}$ & $\begin{array}{l}\text { CTG } \\
(\mathbf{n}=\mathbf{1 6})\end{array}$ & P-value \\
\hline Sex (M/F) & $8 / 4$ & $9 / 7$ & 0.705 \\
Age (years) & $62.4 \pm 20.3$ & $68.0 \pm 9.1$ & 0.767 \\
COPD (II/III/IV) & $4 / 6 / 2$ & $7 / 7 / 2$ & 1.000 \\
FEV1\% pred. & $48.4 \pm 20.9$ & $51.2 \pm 17.3$ & 0.642 \\
6-MWT, m & $553 \pm 67$ & $481 \pm 121$ & 0.077 \\
1-min STST, repetitions & $20.8 \pm 6.0$ & $16.8 \pm 6.3$ & 0.131 \\
5-rep STST, s & $11.9 \pm 2.1$ & $13.9 \pm 4.8$ & 0.642 \\
Arterial hypertension & 10 & 10 & 0.227 \\
Cardiovascular diseases & 12 & 6 & $<0.001$ \\
Cancer & 2 & 4 & 0.595 \\
Diabetes mellitus & 6 & 4 & 0.172 \\
Other & 25 & 20 & \\
\hline
\end{tabular}

COPD: chronic obstructive pulmonary disease; FEV1\% pred.: forced expiratory volume in one second \% of target; 6-MWT: walking distance in 6-min walk test; m: meter; 1-min STST: 1-min sit-to-stand test; 5-rep STST: sit-to-stand test with five repetitions; WBVT: intervention group with whole-body vibration training; CTG: conventional training group.

an expected mean difference of $2.6 \mathrm{~s}$ and an estimated standard deviation (SD) of $2.9 \mathrm{~s}$, result in a targeted case number of 20 patients per group.

The statistical analyses were conducted using the statistics program SPSS 20 (IBM, Inc., USA). For describing the patient population, the results are provided by mean values with SD. For a comparing analysis over time, the Wilcoxon-MannWhitney test (W-test) was applied. To compare the CTG and WBVT group, the difference of the measurement parameters between initial and final measurement was determined. These group differences were analyzed for statistical alterations with the Mann-Whitney U test (U-test). For categorical variables, the Fisher's exact test was applied. All tests were two-tailed, and adopted a significance level of $\mathrm{P}<0.05$.

\section{Results}

Twenty-eight out of 55 patients completed the study and were included in the analysis, 12 from WBVT and 16 from CTG, respectively. Almost half of the patients (49\%) dropped out of the study and did not finish the 12-week period. Reasons for the dropouts are presented in Figure 1. None of the groups' baseline characteristics showed statistically significant differences, except a significant higher number of cardiovascular comorbidities in the WBVT group (Table 1). In Table 2, the initial values of both dropouts and those who completed are compared. The participants in WBVT with the highest initial impairments in exercise capacity (6-MWT and both versions of STST) and lung function (FEV1\% pred.) proved to be more inclined not finishing the study.

Neither the STST, nor the 6-MWD showed significant differences in intra- or intergroup comparison for patients who

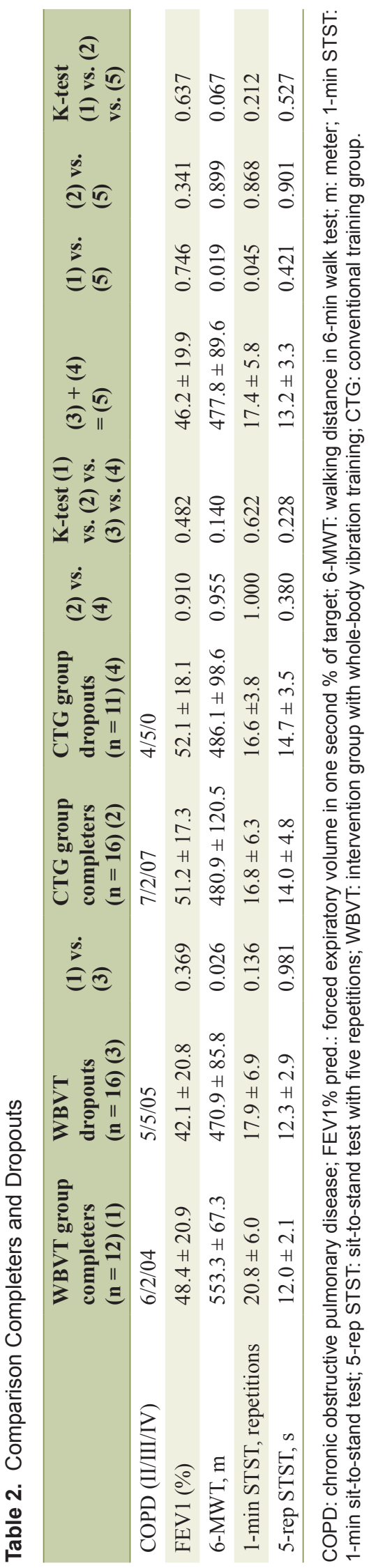


Table 3. Comparison of Treatment Effects

$\begin{array}{llllllllll} & \begin{array}{l}\text { WBVT at } \\ \text { baseline }\end{array} & \begin{array}{l}\text { WBVT at } \\ \text { 3 months }\end{array} & \text { Delta } & \begin{array}{l}\text { Intragroup } \\ \text { P-value }\end{array} & \begin{array}{l}\text { CTG at } \\ \text { baseline }\end{array} & \begin{array}{l}\text { CTG at 3 } \\ \text { months }\end{array} & \begin{array}{l}\text { Delta } \\ \text { Dento }\end{array} & \begin{array}{l}\text { Intragroup Intergroup } \\ \text { P-value }\end{array} \\ \text { PE-value }\end{array}$

FEV1\% pred.: forced expiratory volume in one second \% of target; 6-MWT: walking distance in 6-min walk test; m: meter; pts: points; 1-min STST: 1-min sit-to-stand test; 5-rep STST: sit-to-stand test with five repetitions; WBVT: intervention group with whole-body vibration training; CTG: conventional training group.

completed the study. The quality of life, recorded via the CAT score, improved in the WBVT. Here, the minimal important difference of -2 points was achieved, though it was not reached for the CTG with -0.8 points (Table 3 ). However, the difference was not statistically significant. Quality of life measured by the CRQ showed a significant change for WBVT in the subgroups fatigue $(\mathrm{P}=0.022)$, emotional function $(\mathrm{P}=0.007)$, and mastery $(\mathrm{P}=0.018)$. Furthermore, there was a significant difference between both groups for emotional function $(\mathrm{P}=$ 0.041). An overview of CRQ results is presented in Table 4.

Adverse events, as defined in the protocol, were not observed.

\section{Discussion}

In the present study, no significant effects on exercise capacity could be found with the training protocol used in this study. The primary outcome parameter (STST) did not change significantly in any group. With an improvement of $7 \mathrm{~m}$ (WBVT) and $9 \mathrm{~m}$ (CTG), neither group exceeded the MID of $30 \mathrm{~m}$ for the 6-MWT. These results are not consistent with previous findings. We assume multiple reasons for this. Firstly, participants with the greatest physical impairments, and thus the largest potential for improvement, dropped out of the study especially in the WBVT group due to several reasons. Literature suggests that typically participants with reduced exercise capacity benefit most from physical training [23]. Gloeckl et al demonstrated a statistically significant improvement following a WBVT intervention (+27 m) using WBVT as a complementary exercise modality on top of conventional endurance and strength training [14].

In most training studies, the benefits of training interven- tions are demonstrated during outpatient rehabilitation programs with poorly trained participants. In our study, $71 \%$ of participants $(n=39)$ starting the study took already part in a regular training program. This might explain the relatively high baseline values for exercise capacity (as measured by STST and 6-MWT).

We furthermore assume that a training session only once a week might have been too less, thus neither of the groups showed significant changes. The current training guidelines from the American College of Sports Medicine recommend a training frequency of 3 - 5 times per week [24]. However, these recommendations are difficult to realize for COPD patients in the long-term. Therefore, there seems to be a tradeoff between lower frequency and thus feasible training and the training effect for COPD patients. Despite the rather low training frequency, a high discontinuation rate of $49 \%$ for both groups was observed in our study. Typically, discontinuation rates in training studies are found to be between $20 \%$ and $40 \%$ [25]. Furthermore, the dropout rate in our study was very high compared with dropout rates reported in studies using WBVT in other patient populations [26-28]. However, the dropout rate in both groups was similar and all dropout reasons were not directly related to the intervention (for reasons, Fig. 1). Unfortunately patients who dropped out of the WBVT group were patients with significantly lower exercise capacity compared to completers (Table 2). This might have led to a certain underestimation of WBVT effects, because patients with lower exercise capacity have been shown to have the most potential for improvement [23]. Nevertheless, our results may be interpreted with caution due to the high dropout rate of $49 \%$.

Another cause for the quite low benefit of our 12-week training intervention is the homogeneity in the training content. Both groups performed the same training, with the exception of using WBVT during squat training. Surely, one cannot expect

Table 4. Results $\mathrm{CRQ}$

\begin{tabular}{llllllll} 
& $\begin{array}{l}\text { WBVT at } \\
\text { baseline }\end{array}$ & $\begin{array}{l}\text { WBVT at } \\
\text { 3 months }\end{array}$ & $\begin{array}{l}\text { Intragroup } \\
\text { P-value }\end{array}$ & $\begin{array}{l}\text { CTG at } \\
\text { baseline }\end{array}$ & $\begin{array}{l}\text { CTG at 3 } \\
\text { months }\end{array}$ & $\begin{array}{l}\text { Intragroup } \\
\text { P-value }\end{array}$ & $\begin{array}{l}\text { Intergroup } \\
\text { P-value }\end{array}$ \\
\hline Dyspnea & $4.15 \pm 1.36$ & $4.58 \pm 1.28$ & 0.222 & $4.09 \pm 1.23$ & $4.20 \pm 1.15$ & 0.841 & 0.560 \\
Fatigue & $3.88 \pm 1.25$ & $4.48 \pm 1.32$ & 0.022 & $3.86 \pm 0.89$ & $4.23 \pm 0.92$ & 0.058 & 0.466 \\
Emotional function & $4.08 \pm 1.16$ & $4.92 \pm 1.19$ & 0.007 & $4.27 \pm 1.10$ & $4.43 \pm 0.92$ & 0.421 & 0.041 \\
Mastery & $4.04 \pm 1.21$ & $5.04 \pm 1.40$ & 0.018 & $4.34 \pm 1.30$ & $4.64 \pm 1.28$ & 0.126 & 0.052 \\
\hline
\end{tabular}

$\mathrm{CRQ}$ : Chronic respiratory disease questionnaire; WBVT: intervention group with whole-body vibration training; CTG: conventional training group. 
a large additional training effect by varying only a single and small modality in the context of an entire training concept. This result is in accordance with the conclusions drawn by Salhi et al [25]. Another approach for explaining the lack of improvement is the difficulties associated with standardizing training content, as well as intensity during regular PR. It was not documented, how intensively the participants exercised during the remaining training program (heart rate, $\mathrm{SpO}_{2}$, Borg, etc.)

We nevertheless observed an improvement in the CAT score and partially in the area of health-related quality of life, despite the lack of an increase in exercise capacity in the WBVT group. Some differences in the CRQ domains were statistically significant but not of clinical relevance. However, due to the low number of participants completing the study, we should not over-interpret these results.

There are also some limitations in our study that need to be considered. We have registered a very high dropout rate of $49 \%$, leading to a sample size below the a priori calculated power calculation. Therefore, this major limitation of our study should be taken into account when interpreting our results. The rather high level in baseline exercise capacity for completers limited a higher improvement in exercise capacity by a low frequency training program. In contrast, Salhi et al solely included patients with a 6 -MWT of $<70 \%$ pred. in their study. Potentially our participants also could have benefitted from training with additional weight to induce a sufficient training stimulus [25]. In their systematic review, Gloeckl et al described that especially patients with muscular impairments benefit from WBVT by training solely with their own body weight [15]. Our protocol also did not consider an increase in vibration frequency, which might have further limited the effect of WBVT. Similar to our study the results of the study by Furness et al showed that WBVT did not exacerbate symptoms of COPD [29]. Additionally, our study has shown that patients are at least able to maintain their exercise performance in the context of the 3 months exercise training which can be seen as an important benefit in patients with COPD. However, in another recent study with a small sample size WBVT improved functional capacity in the 6-MWT of patients with COPD undergoing a training program on the vibrating platform as well as in all domains of the SGRQ quality of life in a safe and feasible way [30].

\section{Conclusion}

WBVT was feasible and safe in patients with COPD during an outpatient low frequency exercise program. However, a benefit on exercise capacity could not be demonstrated with the use of an additional WBVT. It is assumed that the reason for this lack of improvement relies in the low volume and intensity of training sessions, calling for studies with higher training frequencies. Additionally, a high dropout rate is further weakening the reliability of this study.

\section{Conflicts of Interest}

The authors have reported that no potential conflicts of inter- est exist with any companies/organizations whose products or services may be discussed in this article.

\section{Author Contributions}

MS and RG contributed to the study hypothesis, study design, writing the manuscript and sharing scientific discussions. JMG contributed to the organization of the study, data collection and sharing scientific discussions. CN contributed to the statistical analysis of the study and data collection. ARK, TB and JHS reviewed the manuscript, and shared scientific discussions. WW contributed to the study design, reviewed the manuscript and shared scientific discussions. All authors have read and approved the manuscript.

\section{References}

1. Goldstein J, Plioplys S, Zelko F, Mass S, Corns C, Blaufuss R, Nordli D. Multidisciplinary approach to childhood epilepsy: exploring the scientific rationale and practical aspects of implementation. J Child Neurol. 2004;19(5):362-378.

2. Griffiths TL, Burr ML, Campbell IA, Lewis-Jenkins V, Mullins J, Shiels K, Turner-Lawlor PJ, et al. Results at 1 year of outpatient multidisciplinary pulmonary rehabilitation: a randomised controlled trial. Lancet. 2000;355(9201):362-368.

3. Puhan MA, Gimeno-Santos E, Scharplatz M, Troosters T, Walters EH, Steurer J. Pulmonary rehabilitation following exacerbations of chronic obstructive pulmonary disease. Cochrane Database Syst Rev. 2011;10:CD005305.

4. Kon SS, Canavan JL, Man WD. Pulmonary rehabilitation and acute exacerbations of COPD. Expert Rev Respir Med. 2012;6(5):523-531; quiz 531.

5. Ries AL, Bauldoff GS, Carlin BW, Casaburi R, Emery CF, Mahler DA, Make B, et al. Pulmonary Rehabilitation: Joint ACCP/AACVPR Evidence-Based Clinical Practice Guidelines. Chest. 2007;131(5 Suppl):4S-42S.

6. Spruit MA, Singh SJ, Garvey C, et al. ATS/ERS Task Force on Pulmonary Rehabilitation, an official American Thoracic Society/European Respiratory Society statement: key concepts and advances in pulmonary rehabilitation. Am J RespirCrit Care Med. 2014;189(12):1570.

7. Troosters T, Gosselink R, Janssens W, Decramer M. Exercise training and pulmonary rehabilitation: new insights and remaining challenges. Eur Respir Rev. 2010;19(115):24-29.

8. Bundesarbeitsgemeinschaft fur Rehabilitation: Rahmenempfehlungen fur den Rehabilitationssport und das Funktionstraining vom 1. Oktober 2003 in der Form vom Januar 2011 Verfugbar unter: www.bar-frankfurt.de.

9. Bundesarbeitsgemeinschaft fur Rehabilitation (BAR) e.V. Rahmenvereinbarung uber den Rehabilitationssport und das Funktionstraining 2011; ISBN 978-3-9813712-5-3.

10. Gohl OC. Training bei COPD. Berchtesgaden 2012. ISBN 978-3-00-040743-7.

11. Spielmanns M, Gohl O, Schultz K, Worth H. [Lung exer- 
cise: outpatient exercise program has long-term benefits on COPD]. Dtsch Med Wochenschr. 2015;140(13):10011005.

12. Merkert J, Butz S, Nieczaj R, Steinhagen-Thiessen E, Eckardt R. Combined whole body vibration and balance training using Vibrosphere(R): improvement of trunk stability, muscle tone, and postural control in stroke patients during early geriatric rehabilitation. Z Gerontol Geriatr. 2011;44(4):256-261.

13. Zha DS, Zhu QA, Pei WW, Zheng JC, Wu SH, Xu ZX, $\mathrm{Li} \mathrm{T}$, et al. Does whole-body vibration with alternative tilting increase bone mineral density and change bone metabolism in senior people? Aging Clin Exp Res. 2012;24(1):28-36.

14. Gloeckl R, Heinzelmann I, Baeuerle S, Damm E, Schwedhelm AL, Diril M, Buhrow D, et al. Effects of whole body vibration in patients with chronic obstructive pulmonary disease - a randomized controlled trial. Respir Med. 2012;106(1):75-83.

15. Gloeckl R, Heinzelmann I, Kenn K. Whole body vibration training in patients with COPD: A systematic review. Chron Respir Dis. 2015;12(3):212-221.

16. Wanger J, Clausen JL, Coates A, Pedersen OF, Brusasco V, Burgos F, Casaburi R, et al. Standardisation of the measurement of lung volumes. Eur Respir J. 2005;26(3):511522.

17. Miller MR, Hankinson J, Brusasco V, Burgos F, Casaburi R, Coates A, Crapo R, et al. Standardisation of spirometry. Eur Respir J. 2005;26(2):319-338.

18. Quanjer PH, Tammeling GJ, Cotes JE, Pedersen OF, Peslin R, Yernault JC. Lung volumes and forced ventilatory flows. Report Working Party Standardization of Lung Function Tests, European Community for Steel and Coal. Official Statement of the European Respiratory Society. Eur Respir J Suppl. 1993;16:5-40.

19. Ozalevli S, Ozden A, Itil O, Akkoclu A. Comparison of the Sit-to-Stand Test with 6 min walk test in patients with chronic obstructive pulmonary disease. Respir Med. 2007;101(2):286-293.

20. ATS statement: guidelines for the six-minute walk test. Am J Respir Crit Care Med. 2002;166(1):111-117.

21. Puhan MA, Behnke M, Frey M, Grueter T, Brandli O,
Lichtenschopf A, Guyatt GH, et al. Self-administration and interviewer-administration of the German Chronic Respiratory Questionnaire: instrument development and assessment of validity and reliability in two randomised studies. Health Qual Life Outcomes. 2004;2:1.

22. Jones PW, Harding G, Berry P, Wiklund I, Chen WH, Kline Leidy N. Development and first validation of the COPD Assessment Test. Eur Respir J. 2009;34(3):648654.

23. Kenn K, Gloeckl R, Soennichsen A, Sczepanski B, Winterkamp S, Boensch M, Welte T. Predictors of success for pulmonary rehabilitation in patients awaiting lung transplantation. Transplantation. 2015;99(5):1072-1077.

24. Pescatello LS, Arena R, Riebe D, et al. Exercise Prescription for other clinical populations: Chronic obtsructive pulmonary disease. Chapter 10. In: ACSM`s Guidelines for Exercise testing and Prescription, 9th Edition. Lippincott: Williams\&Wilkins. 2014; p. 334-337.

25. Salhi B, Malfait TJ, Van Maele G, Joos G, van Meerbeeck JP, Derom E. Effects of Whole Body Vibration in Patients With COPD. COPD. 2015;12(5):525-532.

26. Madou KH, Cronin JB. The Effect of Whole body vibration on physical and physiological capability in special populations. Hong Kong Physiotherapy. 2008;26:24-38.

27. Roth J, Wust M, Rawer R, Schnabel D, Armbrecht G, Beller $\mathrm{G}$, Rembitzki I, et al. Whole body vibration in cystic fibrosis - a pilot study. J Musculoskelet Neuronal Interact. 2008;8(2):179-187.

28. Rietschel E, van Koningsbruggen S, Fricke O, Semler O, Schoenau E. Whole body vibration: a new therapeutic approach to improve muscle function in cystic fibrosis? Int J Rehabil Res. 2008;31(3):253-256.

29. Furness T, Joseph C, Naughton G, Welsh L, Lorenzen C. Benefits of whole-body vibration to people with COPD: a community-based efficacy trial. BMC Pulm Med. 2014;14:38.

30. Braz Junior DS, Dornelas de Andrade A, Teixeira AS, Cavalcanti CA, Morais AB, Marinho PE. Whole-body vibration improves functional capacity and quality of life in patients with severe chronic obstructive pulmonary disease (COPD): a pilot study. Int J Chron Obstruct Pulmon Dis. $2015 ; 10: 125-132$. 